\title{
Relationship between Caretakers Variable on Education and Coping Strategies of Caretakers Attending to Patients with Cancer Problems
}

\author{
M. Sandhya $\operatorname{Rani}^{1 *}$, Dr. Nasreenbanu ${ }^{2}$
}

\section{ABSTRACT}

The present study makes an attempt to understand the Relationship between Caretaker Variable on Education and Coping Strategies of Caretakers Attending to Patients with Cancer Problems. Caretakers who were ready and willing to extend their cooperation for in-depth interview were selected as population for the study. Thus a total number of 80 caretakers were selected purposively for conducting the present study. The results revealed that caretakers used both approach and avoidance coping styles. Better the education, caretakers were used it for medical treatment and for providing medicines etc. for the sick patient.

Keywords: Education, Caretakers, Coping Strategies, Cancer Problems

Becoming a parent, is one of the most powerful of the human experiences, is often accompanied with feelings of celebration and relief, but it can also be a time of anxiety, and stress. The term "Parenting" is derived from the Latin root pario, meaning life-giver, and encompasses much more than just the care giving activities parents perform.

The health status of a child, including the onset of a chronic illness, is one of many factors that can contribute to the quality of child rearing (Kazak, 1989). When considering that up to 30\% of children have a chronic health condition (Newacheck and Halfon, 1998), 11\% of whom are living with conditions considered moderate to severe (Newacheck, Stoddard and McManus, 1993), a significant number of families are faced with an even more challenging future than they had anticipated. How parents respond to this situation can affect both the short- and long-term developmental outcomes for their children.

\footnotetext{
${ }^{1}$ Department Of Human Development And Family Studies, College Of Home science, Professor Jayashankar Telangana State Agricultural University, Hyderabad India

2 Principal Scientist,AICRP- Human Development, PG \& RC, Professor Jayashankar Telangana State Agricultural University, Hyderabad India

*Responding Author

Received: February 3, 2017; Revision Received: March 19, 2017; Accepted: March 23, 2017

(C) 2017 Mitra D; licensee IJIP. This is an Open Access Research distributed under the terms of the Creative Commons Attribution License (www.creativecommons.org/licenses/by/2.0), which permits unrestricted use, distribution, and reproduction in any Medium, provided the original work is properly cited.
} 


\section{Relationship between Caretakers Variable on Education and Coping Strategies of Caretakers Attending}

to Patients with Cancer Problems

Jemal et al. (2011) reported that in 2008, there were approximately 12.7 million cancer cases reported worldwide.

Hodgkison et al. (2007) found that statistically the cancer rates are on the rise. Approximately $33 \%$ of males and $25 \%$ of females will get cancer before the age of 75 .

Othman et al. (2011) found that Parents with higher cancer knowledge reported reduced stress $(p<0.01)$ and anxiety $(p<0.05)$. Highly educated parents engaged in more activities with their children $(\mathrm{p}<0.05)$. Parental anxiety was correlated significantly with children's current treatment including procedure $(\mathrm{p}<0.01)$, 'In-patient' Vs 'Outpatient' $(\mathrm{p}<0.01)$, and children's condition $(p<0.01)$. Parents of hospitalized children who underwent chemotherapy were significantly more anxious than their counterparts. Parents who perceived theirs children's current condition as very good', reported reduced anxiety, compared to those who reported their child's condition as 'ok'. The more psychological problems the children had, the higher parental anxiety $(\mathrm{p}<0.05)$ and stress symptoms $(\mathrm{p}<0.01)$.

\section{RESEARCH METHODOLOGY}

A total number of 80 caretakers who were ready and willing to extend their cooperation for in depth interview were selected as population for the present study. The sample was limited to caretakers for two reasons. First much of the research on family care giving which has been done in aboard only this area of study is almost non- existent in the state of Telangana. Secondly, reports have suggested that parents are particularly vulnerable to the strains of illness experienced due to multiple roles to be shouldered. The main focus of the study was to provide various alternative strategies for the caretakers.

\section{RESEARCH FINDINGS AND DISCUSSION}

\section{Research Findings and Discussion}

Caretakers who were ready and willing to extend their cooperation for in depth study were selected as population for the study that is "Relationship between Caretakers Variable on Education and Coping Strategies of Caretakers Attending to Patients with Cancer Problems". Thus a total 80 caretakers were selected purposively for conducting the present study.

\section{Description of the Cancer Problems}

1. Cancer illness is the most acute pressure, which any family may experience and it also creates a potential threat equally to both the victim and the caretaker.

2. For the patient, the threat involves painful medical procedures, surgeries, and its side effects, and frequent hospitalization.

(C) The International Journal of Indian Psychology, ISSN 2348-5396 (e)| ISSN: 2349-3429 (p) | 150 
Relationship between Caretakers Variable on Education and Coping Strategies of Caretakers Attending to Patients with Cancer Problems

\section{Relationship between Caretakers Variable on Education and Coping Strategies}

\begin{tabular}{|l|l|l|l|}
\hline \multicolumn{2}{|c|}{ Approach coping } & \multicolumn{2}{c|}{ Avoidance coping } \\
\hline \multicolumn{2}{|c|}{ Caretaker Variable: Education } \\
\hline Logical Analysis & $0.36^{* *}$ & Cognitive Avoidance & 0.15 \\
\hline Positive Appraisal & 0.29 & Acceptance & $0.32^{*}$ \\
\hline Guidance and Support & $0.32^{* *}$ & Alternative Rewards & $0.33^{* *}$ \\
\hline Problem Solving & $0.30^{*}$ & Emotional Discharge & $-0.49 * *$ \\
\hline
\end{tabular}

$\mathrm{P} * 0.05$; level of significance; $\mathrm{P} * * 0.01$, level of significance, $\mathrm{r}$ tab value at $5 \%$ level of significance $=0.2500 ; \mathrm{r}$ tab value at $1 \%$ level of significance is 0.3248 .

The above table presents the relationship between caretaker variable on education and coping strategies of caretakers attending to children with cancer problems. Out of the eight coping responses, the first four represents Approach coping and the remaining four comes under Avoidance coping.

Under Approach coping, the first area is logical analysis, which deals with handling the situation objectively, finding some personal meaning to the situation and anticipating the new demands. In this area, the level of significance is $0.36^{* *}$ logical analysis in coping with the situation.

The second area under Approach coping is Positive appraisal, which includes caretaker's ability to see the good side of the situation and how the event could change one's life in a positive way. In this area, the level of significance is 0.29 positive appraisals in coping with the situation.

The third area under Approach coping is guidance and support, which involves seeking support from relations, talking to a closed person about the problem and praying for guidance and strength. In this area, the level of significance is $0.32 * *$ caretakers sought guidance and support.

The fourth area under Approach coping is problem solving, which involves a plan of action, using alternate ways of solving problem and trying out new ways of confronting the problem. In this area, the level of significance is $0.30 *$ used to problem solving strategies.

Under Avoidance coping, the first area is cognitive avoidance i.e. avoiding the situation, denial, day dreaming, and imagining that problems would go away on their own. In this area, level of significance is 0.15 used cognitive avoidance.

The second area under avoidance coping is acceptance i.e., accepting the situation with all its intensity, realizing that one has no control over the problem and believing that outcome would be decided by fate. In this area, the level of significance is $0.32 *$. 


\section{Relationship between Caretakers Variable on Education and Coping Strategies of Caretakers Attending to Patients with Cancer Problems}

The third area under avoidance coping is seeking alternate rewards i.e., getting involved in new activities, making new friends and indulging in more recreational activities. In this area, the level of significance is $0.33^{* *}$.

The fourth area under avoidance coping is emotional discharge, which involves yelling or shouting to let off steam, showing the frustration of role capacity on others and keeping away from people in general. In this area, the level of significance is $-0.49 * *$ used avoidance coping emotional discharge technique.

\section{CONCLUSION}

The data collected with respect to relationship between caretaker variable on education and coping strategies of caretakers attending to patients with cancer problems revealed that caretakers used both approach and avoidance coping styles. It indicated that Education of the care taker has significant positive relationship with logical analysis and guidance seeking dimension of approach coping strategies. There was no significant relationship between education and positive appraisal, problem solving coping strategies. Education was found to have significant positive relationship with alternative rewards and significant negative relationship with emotional discharge of avoidance coping strategy. There was no significant relationship between education and problem solving, cognitive avoidance, resigned acceptance of coping strategies. Better the education, caretakers were used it for medical treatment and for providing medicines etc. for the sick child.

\section{Acknowledgments}

The author appreciates all those who participated in the study and helped to facilitate the research process.

Conflict of Interests: The author declared no conflict of interests.

\section{REFERENCES}

Hagedoorn, M., Sanderman, R., Bolks, H. N., Tuinstra, J and Coyne, J. C. (2008).Distress in couples coping with cancer: A meta-analysis and critical review of role and gender effects. Psychological Bulletin, 133(1), 1-30.

Hodgkinson, K., Butow, P., Hunt, G. E., Pendlebury, S., Hobbs, K. M., Lo, S. K and Wain, G. (2007). The development and evaluation of a measure to assess cancer survivors' unmet supportive care needs: the (Cancer Survivors' Unmet Needs measure). Psycho-oncology 16(9) : 796-804.

Jemal, A., Bray, F., Center, M. M., Ferlay, J., Ward, E and Forman, D. (2011).Global cancer statistics. A Cancer Journal for Clinicians 61(2): 69-90. 
Relationship between Caretakers Variable on Education and Coping Strategies of Caretakers Attending to Patients with Cancer Problems

Kazak, A.E. 1989. Families of Chronically Ill Children: A Systems and Social- Ecological. Model of Adaptation and Challenge. Journal of Consulting and Clinical Psychology. 57: 25-30.

Newacheck, P.W and Halfon, N.1998. Prevalence and Impact of Disabling Chronic. Conditions in Childhood. American Journal of Public Health. 88: 610-617.

Newacheck, P.W., Stoddard, J.J and McManus, M.1993. Ethno cultural Variations in the Prevalence and Impact of Childhood Chronic Conditions. Pediatrics. 91: 1031-1039.

How to cite this article: Rani S, Nasreenbanu (2017), Relationship between Caretakers Variable on Education and Coping Strategies of Caretakers Attending to Patients with Cancer Problems, International Journal of Indian Psychology, Volume 4, Issue 2, No. 94, ISSN:2348-5396 (e), ISSN:2349-3429 (p), DIP:18.01.155/20170402, ISBN:978-1-365-84229-0

(c) The International Journal of Indian Psychology, ISSN 2348-5396 (e)| ISSN: 2349-3429 (p) | 153 